\title{
REVISIÓN \\ Bacteriología asociada al cultivo de moluscos en Chile. Avances y perspectivas
}

\author{
Bacteriology associated to mollusc culture in Chile. Advances and perspectives
}

\author{
Mery de la Fuente ${ }^{1,2}$, Claudio Miranda ${ }^{3}$ y Víctor Faúndez ${ }^{1}$
}

\begin{abstract}
'Laboratorio de Genómica y Biotecnología Aplicada, Departamento de Ingeniería Ambiental y Recursos Naturales, Facultad de Ingeniería, Universidad Católica de la Santísima Concepción, Alonso de Ribera 2850, Concepción, Chile. vfaundez@ucsc.cl 2Departamento de Ciencias Biológicas y Químicas, Facultad de Ciencia, Universidad San Sebastián, General Cruz 1577, Concepción, Chile

${ }^{3}$ Laboratorio de Patobiología Acuática, Departamento de Acuicultura, Facultad de Ciencias del Mar, Universidad Católica del Norte, Larrondo 1281, Coquimbo, Chile
\end{abstract}

\begin{abstract}
Excessive fishing effort has led to overexploitation and depletion of major benthic fisheries in Chile, so it has been encouraged cultivation of major overexploited benthic resources in controlled environments, mainly those which are not possible to collect seeds from environment. In this review, the current knowledge on bacteriology associated with shellfish farming in controlled systems in Chile, including both aspects associated with development of infectious diseases of bacterial aetiology as well as the use of microorganisms to reduce mortality of cultured species, is described. The majority of bacteriological studies in Chilean shellfish culture were done in the Chilean scallop, Argopecten purpuratus and were related to identifying pathogens isolated from mass mortalities occurred in larval and/or juvenile cultures and the verification of their pathogenic activity performing bioassays under controlled condition bioassays. There are also a large number of studies on bacteria exhibiting inhibitory activities against shellfish pathogenic and their protective effects under controlled conditions. Despite the above, still are required more studies to know the structure and dynamics of the microbiota associated to mollusk culture, bacterial pathogens and molecular elements encoding for their pathogenicity.
\end{abstract}

Key words: Molluscs, bacteria, larval cultures, probiotic, pathogen

Resumen.- El excesivo esfuerzo pesquero ha conducido a la sobrexplotación y agotamiento de las principales pesquerías bentónicas en Chile, lo que ha incentivado el cultivo de los principales recursos bentónicos en ambientes controlados, particularmente de aquellos en los que no es posible recolectar semillas del medio ambiente. En la presente revisión bibliográfica se describe la literatura actualizada sobre el conocimiento bacteriológico relacionado con el cultivo de moluscos en sistemas controlados en Chile, tanto en aspectos asociados al desarrollo de patologías infecciosas de etiología bacteriana así como del uso de microorganismos para reducir los niveles de mortalidad de las especies en cultivo. La mayoría de los estudios bacteriológicos en cultivos de moluscos en Chile se han realizado en el ostión del norte, Argopecten purpuratus y se han referido a la identificación de patógenos aislados de mortalidades masivas ocurridas en cultivos de larvas y/o juveniles y la verificación de su actividad patogénica mediante la realización de bioensayos realizados en condiciones controladas. También existe un número importante de estudios de bacterias con capacidades inhibitorias de patógenos de moluscos y sus efectos protectores en condiciones controladas. A pesar de lo anterior, aún se requieren mayores estudios para conocer la estructura y dinámica de la microbiota asociada al cultivo de moluscos, los patógenos bacterianos y los elementos moleculares que codifican para su patogenicidad.

Palabras clave: Moluscos, bacteria, cultivos larvales, probiótico, patógeno

\section{INTRODUCCIÓN}

El cultivo intensivo de bivalvos en sistemas de ambiente controlado o hatcheries se inició en los años 60, primero con la ostricultura, y luego con la mitilicultura, con el objetivo de abastecer de semillas a centros de cultivos destinados a la comercialización de estos recursos marinos. En la actualidad, la sobrexplotación y agotamiento de las principales pesquerías bentónicas a lo largo de las costas de Chile, convierte al hatchery en una fuente continua de semillas durante la época estival. Este sistema de cultivo es de vital interés para el cultivo de muchas especies de recursos bentónicos de alto valor económico para las cuales no existe la alternativa de la captación natural mediante colectores en el mar, a diferencia de lo que ocurre en bahía Tongoy para el caso del ostión del norte y en el sur de Chile, para la mitilicultura (Wurmann-Gotfrit 2008). Dada esta situación, en los 
últimos años se ha incentivado la investigación científica para mejorar la tasa de producción de semillas en hatchery, con el objeto de establecer las condiciones óptimas de cultivo (Martínez-Guzmán 2008). El mayor desarrollo se ha obtenido para la pectinicultura en el norte del país permitiendo la producción sostenida a nivel comercial de esta especie (Uriarte 2008).

Mediante algunos estudios se ha evidenciado el efecto de parámetros como la temperatura, nutrición, salinidad, pH y densidad larval en el cultivo en ambiente controlado de diversos recursos bentónicos (Farias et al. 1997, Uriarte 2008, Gallardo \& Cancino 2009). Las condiciones intensivas del cultivo larval pueden favorecer el crecimiento de bacterias debido a la disponibilidad y acumulación de metabolitos y productos de excreción provenientes de las larvas que podrían servir de nutrientes para los microorganismos copiotróficos asociados a estos ambientes. Por otra parte, se ha observado una tasa de crecimiento menor de semillas de A. purpuratus producidas en hatchery, en comparación a aquellas provenientes de ambiente natural (Pérez et al. 2012), sugiriendo que una pérdida de heterocigocidad en la población en cultivo pudiera ser un factor determinante para esta diferencia.

El desarrollo de cuadros patológicos en etapas tempranas de moluscos en cultivo es favorecido en muchas ocasiones por una mayor susceptibilidad de las larvas debido a condiciones inadecuadas tales como alta densidad larval, altos niveles de materia orgánica y concentraciones bajas de oxígeno disuelto, facilitando la multiplicación de agentes bacterianos de carácter oportunista (Wurmann-Gotfrit 2008). Estos cuadros infecciosos producen mortalidades masivas que con frecuencia producen la pérdida total de los batches larvales y el suministro de semillas, con serias consecuencias económicas para la sustentabilidad del proceso productivo (Romalde \& Barja 2010). Sin embargo, existe una carencia de estudios que permitan dilucidar la cronología de estos cuadros patológicos y los mecanismos de virulencia que expresan sus agentes etiológicos (Prado et al. 2010). Por lo general, el agente etiológico de estos brotes no es identificado, y los acuicultores se ven obligados a repetir o reiniciar el proceso de producción larval con la incertidumbre de controlar dichos brotes patológicos o las causas que la provocan (Wurmann-Gotfrit 2008). Las infecciones afectan principalmente a los estados larvales y postlarvales previo a su traspaso al ambiente natural. En el último tiempo, el mayor conocimiento sobre la función de la microbiota asociada a estados larvales y la aplicación de bacterias benéficas a los cultivos se vislumbra como una buena estrategia para el control de patógenos.

En la presente revisión se describen y analizan los principales avances obtenidos mediante la realización de estudios realizados en Chile sobre las condiciones bacteriológicas de algunos cultivos de moluscos de interés comercial y la factibilidad del manejo de su microbiota para aumentar su producción.

\section{Microbiota asociada al CUltivo de moluscos}

El conocimiento de la microbiota asociada a los cultivos de moluscos en ambientes controlados es fundamental para implementar estrategias de control sanitario que eviten la aparición de infecciones y a la vez permitan asimilar las condiciones del cultivo artificial a las condiciones naturales de crecimiento en el mar. Es así que se han realizado diversos estudios para caracterizar y conocer la composición de la microbiota asociada a estos cultivos, con especial referencia al ostión del norte, A. purpuratus (Riquelme et al. 1994, 1995b; Jorquera et al. 2001). En uno de estos estudios se detectó la presencia de bacterias en las gónadas de los reproductores, observando el predominio de cepas pertenecientes a los géneros Acinetobacter, Pseudomonas, Vibrio y Moraxella, aunque esta identificación no fue realizada mediante técnicas moleculares (Riquelme et al. 1994).

También se han detectado bacterias predominantemente Gram negativas en la hemolinfa de ejemplares adultos de $A$. purpuratus, comportándose como microbiota normal (García-Tello et al. 2002). Además, se ha caracterizado la población de bacterias cultivables presentes en los cultivos larvales y post-larvales de A. purpuratus, encontrándose una mayor abundancia de los géneros Pseudoalteromonas, Bacillus, Marinobacterium, Alteromonas y Vibrio en larvas (Godoy et al. 2011) y del género Vibrio en post-larvas (Avendaño et al. 2001).

En un estudio realizado para caracterizar la microbiota bacteriana asociada a las primeras etapas del desarrollo de A. purpuratus se observó un predominio de representantes de los géneros Pseudomonas, Moraxella y Vibrio durante los procesos de desove realizados en condiciones de laboratorio. Al analizar la actividad de algunas cepas de estos géneros se pudo detectar la ocurrencia de actividad inhibitoria sobre la capacidad natatoria de larvas de A. purpuratus (Riquelme et al. 1995b). En contraposición, Llanos et al. (2002) encontraron un porcentaje importante de bacilos Gram positivos 
formadores de esporas y cocáceas no formadoras de esporas, microorganismos no habituales en moluscos bivalvos. Sin embargo, estos autores también reportaron niveles importantes de Vibrio spp. en diversos tejidos como branquias, glándula digestiva, gónadas e intestino de individuos adultos de A. purpuratus, lo que está en concordancia con otros estudios bacteriológicos en esta especie (Riquelme et al. 1995b, Leyton \& Riquelme 2008a).

Sin embargo, a pesar del avance en el conocimiento de la microbiota asociada al cultivo de $A$. purpuratus, aún existe un gran desconocimiento sobre la bacteriología asociada a otros recursos bentónicos de interés comercial en Chile, tales como Haliotis rufescens, Haliotis discus hannai, Concholepas concholepas, Mytilus chilensis, Mesodesma donacium y Tiostrea chilensis. Dentro de estos recursos hidrobiológicos, se destaca un estudio realizado en ejemplares adultos de $C$. concholepas, donde se describió a Vibrio spp. como el género predominante en el intestino, junto a Acinetobacter spp. y Moraxella spp. (Márquez et al. 1990). En relación a otras especies de moluscos en cultivo, Romero et al. (2002) identificaron al género Arcobacter como componentes abundantes de la microbiota de especímenes adultos de la ostra chilena Tiostrea chilensis provenientes de hatcheries del sur de Chile. En un estudio anterior, Romero \& Espejo (2001) determinaron, mediante métodos bacteriológicos y moleculares, que menos del $0,001 \%$ de los componentes de la microbiota de $T$. chilensis son cultivables en medios bacteriológicos, lo que indica la gran diversidad bacteriana que no puede ser estudiada mediante cultivo y que pudiera estar ejerciendo una función importante para el crecimiento larval.

En los últimos años, con la aplicación de técnicas moleculares, se ha logrado detectar la gran diversidad de especies bacterianas que interactúan con los moluscos y la función ecológica que ellas cumplen en el crecimiento de estos recursos. Técnicas como el DGGE (Denaturing Gradient Gel Electrophoresis) de fragmentos de ADNr 16S permiten el análisis de comunidades bacterianas completas (Sandaa et al. 2003), incluyendo la porción de bacterias no cultivables. La estandarización de técnicas moleculares como la hibridación por fluorescencia in situ (FISH) con sondas específicas para $\gamma$-proteobacterias y Vibrio sp. ha permitido determinar la abundancia total de estas bacterias en el bacterioplancton asociado a cultivos larvales masivos en hatcheries comerciales en el norte de Chile (Jorquera et al. 2004). El desarrollo de estas técnicas moleculares y otras basadas en la secuenciación del gen $\mathrm{ADNr} 16 \mathrm{~S}$ para distintos patógenos, puede ser una herramienta efectiva para la detección rápida de patógenos, especialmente en una etapa previa a la infección cuando los patógenos se encuentran aún en bajas concentraciones para ser detectados por técnicas de cultivo, ya que la sensibilidad de las técnicas moleculares es mucho mayor a la del cultivo tradicional en placa. Mediante la realización de estudios de las comunidades bacterianas asociadas a los cultivos de moluscos, se ha podido demostrar los beneficios que otorga una microbiota estable para el crecimiento larval. Un estudio realizado en un cultivo en hatchery sin tratamiento antibiótico, generó post-larvas con una microbiota más estable, que evitaría que las larvas sean colonizadas por bacterias oportunistas, factor importante para aumentar la sobrevivencia en el traspaso de las larvas al medio natural (Avendaño et al. 2001). Además, se determinó que si el agua de mar que llega a los estanques de cultivo es filtrada con un diámetro de poro amplio (5 $\mu \mathrm{m})$, se obtiene una sobrevivencia y crecimiento mayor de las larvas de A. purpuratus que cuando se filtra con un tamaño de poro menor ( $2 \mu \mathrm{m})$ (Riquelme et al. 1997).

Tratamientos en el Cultivo de moluscos para el CONTROL DE INFECCIONES BACTERIANAS

Una de las estrategias más utilizadas para el control de los niveles bacterianos en los hatcheries de moluscos en Chile corresponde al tratamiento físico del agua a utilizar en los estanques de cultivo larval, realizado por filtraciones en serie y una posterior irradiación con luz ultravioleta (UV), junto con el recambio de agua de los estanques de cultivo larval de manera diaria o cada dos días. Estas estrategias de control sanitario son muy efectivas para disminuir los niveles de materia orgánica, material particulado y carga bacteriana pero tienen la desventaja de ser poco selectivos a nivel microbiológico produciendo la eliminación tanto de las bacterias benéficas como de las patógenas, con la consiguiente reducción de la microbiota del cultivo, favoreciendo la colonización por microorganismos oportunistas no deseados provenientes de otras fuentes de ingreso, como larvas $\mathrm{y} /$ alimento microalgal, debido a la disponibilidad de nichos disponibles en el sistema de cultivo (Prado et al. 2010).

La industria farmacéutica ha desarrollado una vasta gama de productos químicos comerciales para el control de patógenos microbianos y prevención de enfermedades, principalmente para satisfacer la demanda de la industria acuícola de peces salmonídeos. No obstante, debido a que la acuicultura de recursos bentónicos no es una 
actividad masificada a nivel nacional, aún no se dispone en el mercado de productos farmacológicos autorizados para el control de infecciones bacterianas en los sistemas de producción de moluscos, lo que ha determinado la necesidad del uso extra etiqueta de aquellos fármacos autorizados para su uso en el cultivo de salmónidos, algunos de los cuales han demostrado una gran eficiencia para obtener un aumento en el crecimiento y la sobrevivencia larval de moluscos en cultivo (Uriarte et al. 2001, Miranda et al. 2014). Es así que Miranda et al. (2014) evidenciaron que un tratamiento con florfenicol administrado directamente en el estanque de cultivo larval es eficiente para asegurar niveles adecuados de supervivencia larval en sistemas de cultivo comercial. Sin embargo, la incidencia de niveles importantes de bacterias resistentes a este fármaco permite argüir que la efectividad de este antimicrobiano para evitar episodios de mortalidades masivas pudiera no mantenerse en el mediano plazo si se sigue utilizando de manera intensiva y sin regulación en la industria pectinicultora nacional (Miranda et al. 2013). Otros estudios han demostrado que los tratamientos con oxitetraciclina no son efectivos para reducir en niveles significativos el contenido bacteriano de larvas de ostión del norte y consecuentemente producir un aumento en los niveles de supervivencia larval (Godoy et al. 2011, Miranda et al. 2013).

\section{Patógenos bacterianos asociados al Cultivo de MOLUSCOS}

En la actualidad se cuenta con pocos estudios que identifiquen a los patógenos bacterianos causantes de cuadros patogénicos en larvas y juveniles de moluscos en cultivo, pero cuando estos se han identificado, por lo general se ha comprobado que producen niveles altos de mortalidades en condiciones controladas a pequeña escala (Tabla 1). La mayoría de los estudios que identifican a patógenos de cultivos de moluscos y caracterizan su actividad patogénica se relacionan con mortalidades en cultivos larvales del ostión del norte, A. purpuratus (Riquelme et al. 1995a, 1996b; Rojas et al. 2009).

Tabla 1. Patógenos bacterianos asociados a cultivos de moluscos en Chile / Bacterial pathogens associated to mollusc culture in Chile

\begin{tabular}{|c|c|c|c|c|c|}
\hline Especie cultivada & Etapa & Especie patógena & $\begin{array}{l}\text { Biensayo de patogenicidad o } \\
\text { estudio realizado } \\
\text { (Inóculo bacteriano, Densidad de } \\
\text { moluscos desafiados, Volumen } \\
\text { final, Tiempo desafío) }\end{array}$ & Ensayo & Referencia \\
\hline Argopecten purpuratus & Larval & Vibrio anguillarum & $\begin{array}{l}10^{4-} 10^{8} \text { cel } \mathrm{mL}^{-1}, 2 \text { larvas } \mathrm{mL}^{-1} \\
15 \mathrm{~mL}, 24 \mathrm{~h}\end{array}$ & in vivo & Riquelme et al. 1995a \\
\hline Argopecten purpuratus & Larval & Aeromonas hydrophila & $\begin{array}{l}5,5 \times 10^{2}-5,5 \times 10^{4} \text { cel mL }^{-1} \\
2-3 \text { larvas } \mathrm{mL}^{-1}, 15 \mathrm{~mL}, 24 \mathrm{~h}\end{array}$ & in vivo & Riquelme et al. 1996b \\
\hline Argopecten purpuratus & Larval & Vibrio alginolyticus & $\begin{array}{l}5,5 \times 10^{4}-5,5 \times 10^{2} \text { cel mL }{ }^{-1}, \\
2-3 \text { larvas } \mathrm{mL}^{-1}, 15 \mathrm{~mL}, 24 \mathrm{~h}\end{array}$ & in vivo & Riquelme et al. 1996b \\
\hline Argopecten purpuratus & Larval & Halomonas sp. & $\begin{array}{l}10^{5} \mathrm{cel} \mathrm{mL}^{-1}, 10 \text { larvas } \mathrm{mL}^{-1} \\
300 \mathrm{~mL}, 48 \mathrm{~h}\end{array}$ & in vivo & Rojas et al. 2009 \\
\hline Argopecten purpuratus & Larval & Vibrio splendidus & $\begin{array}{l}1,0 \times 10^{6} \text { ufc } \mathrm{mL}^{-1}, 20 \text { larvas } \mathrm{mL}^{-1} \\
4 \mathrm{~mL}, 48 \mathrm{~h}\end{array}$ & in vivo & Rojas et al. 2014 \\
\hline Haliotis rufescens & Adulto & $\begin{array}{l}\text { Candidatus Xenohaliotis } \\
\text { californiensis }\end{array}$ & Sin bioensayo & & $\begin{array}{l}\text { Campalans \& Lohrmann } \\
2009\end{array}$ \\
\hline Haliotis rufescens & Adulto & $\begin{array}{l}\text { Candidatus Xenohaliotis } \\
\text { californiensis }\end{array}$ & Sin bioensayo & & González et al. 2012 \\
\hline
\end{tabular}


Es así que Riquelme et al. (1995a) comprobaron la actividad patogénica en condiciones experimentales sobre larvas de $A$. purpuratus de una cepa de $V$. anguillarum-related (VAR) aislada de un episodio de mortalidad masiva desarrollado en un cultivo comercial y pudieron comprobar que su virulencia estaba mediada principalmente por la producción de exotoxinas. En otro estudio, Riquelme et al. (1996b) aislaron cepas de Aeromonas hydrophila como la población predominante en una muestra de larvas de A. purpuratus moribundas y cepas de Vibrio alginolyticus provenientes del cultivo y demostraron su actividad patogénica sobre larvas de $A$. purpuratus. Posteriormente, se demostró la participación de una cepa de Halomonas sp. sobreproductora de exopolisacárido en procesos de mortalidad de larvas de A. purpuratus en cultivos intensivos, causando la aglutinación larval y un bloqueo de la actividad ciliar conduciendo a la muerte larval por cese del movimiento y acumulación de larvas en el fondo del estanque de cultivo (Rojas et al. 2009). En un estudio reciente, Rojas et al. (2014) aislaron 3 cepas de Vibrio splendidus desde mortalidades masivas de larvas de A. purpuratus ocurridas en cultivos comerciales localizados en el norte de Chile y confirmaron su actividad patogénica mediante el cumplimiento de los postulados de Koch. En este estudio se evidenció que las cepas de V. splendidus presentaban diferentes niveles de virulencia y que la actividad patogénica estaba mediada principalmente por componentes extracelulares termoestables no proteicos. Los autores concluyeron que para evitar el colapso del cultivo se debe cautelar por mantener en el estanque de cultivo larval concentraciones de esta especie menores a $10^{4}$ unidades formadores de colonias por $\mathrm{mL}$.

En su mayoría estos patógenos son de carácter oportunista, y se encuentran en el medio circundante al cultivo (Elston 1984). Por lo general, se han establecido 3 rutas importantes de ingreso de bacterias patógenas al cultivo: 1) el agua del afluente, en particular si esta no es tratada, 2) el alimento microalgal y 3) los reproductores a utilizar en el desove (Elston 1984). Algunos estudios han establecido que una reducción de la concentración bacteriana presente en los estanques de cultivo es una condición obligada para reducir los niveles de mortalidad larval en cultivos de ostiones (Jorquera et al. 2001, Miranda et al. 2014), y en particular los niveles de Vibrio puesto que muchos representantes de este grupo exhiben una reconocida actividad patogénica sobre diversas especies de moluscos en sistemas de cultivo controlado (Leyton \& Riquelme 2008a). También existen algunos estudios que sugieren que los reproductores pueden ser una puerta de entrada de Vibrio spp. al cultivo larval de pectínidos, al ser detectados en las gónadas de ejemplares adultos de A. purpuratus (Di Salvo 1990, Chávez \& Riquelme 1994), pudiéndose demostrar su transmisión vertical (Riquelme et al. 1994). Adicionalmente, Di Salvo (1994) observó la presencia frecuente de Vibrio spp. en reproductores de A. purpuratus y sugirió que uno de los factores primordiales para el fracaso del cultivo en hatchery sería la ocurrencia de infecciones crónicas subletales en el stock reproductor, lo que coincide con lo reportado por Sainz-Hernández \& Maeda-Martínez (2005) quienes demostraron que los reproductores del molusco Argopecten ventricosus cumplen una función muy importante en el ingreso de Vibrio spp. en los hatcheries implementados para el cultivo de esta especie, aunque también demostraron su presencia en el alimento microalgal.

Algunos estudios realizados en las primeras etapas del desarrollo del abalón rojo, $H$. rufescens, detectaron niveles de mortalidad cercanas al $100 \%$ en la etapa de post-larva, detectándose la presencia de las especies de Vibrio, $V$. vulnificus, $V$. hollisae, V. fischeri y mayoritariamente $V$. splendidus biotipo II, aunque no se comprobaron los postulados de Koch, requisito esencial para confirmar a estas especies como los causantes de tales mortalidades (Faune 2003).

Por otra parte, la ocurrencia de otros patógenos procariontes como Candidatus Xenohaliotis californiensis y organismos tipo rickettsiales (Rickettsia-Like Organisms, RLO) han sido detectados mediante el uso de técnicas histológicas en $H$. rufescens y A. purpuratus, respectivamente (Lohrmann et al. 2002, Campalans \& Lohrmann 2009, Lohrmann 2009). Asimismo, se han detectado RLO en ejemplares de Perumytilus purpuratus (Montenegro et al. 2012).

El creciente desarrollo de la industria abalonera en Chile (Flores-Aguilar et al. 2007) ha generado una expansión de algunas patologías asociadas a este recurso, en especial de la bacteria patógena Candidatus Xenohaliotis californiensis que produce el síndrome de pie marchitado (withering syndrome), sobre H. rufescens (Enríquez \& Villagrán 2008). Esto ha determinado que este patógeno haya sido incluido en la Lista 2 del Reglamento de Medidas de Protección, Control y Erradicación de la Enfermedades de Alto Riesgo para las Especies Hidrobiológicas (RESA), lo que implica la obligatoriedad de que todos los centros de cultivo estén sujetos a monitoreos anuales. Aunque la prevalencia de esta 
patología no es alta y es altamente dependiente de la temperatura, ha comenzado a ser sujeta de algunos estudios. Es así que González et al. (2012) concluyeron que una infección temprana por este patógeno afecta negativamente la actividad fisiológica de $H$. rufescens, aunque ésta sea asintomática. En un estudio posterior, se ensayó la hibridación inter-específica de las especies $H$. rufescens y $H$. discus hannai para obtener un híbrido resistente a esta patología, pero éste también exhibió susceptibilidad a este patógeno (González et al. 2014).

Es evidente que se requieren de más estudios que permitan el aislamiento de los agentes infecciosos causantes de los episodios recurrentes de mortalidades masivas en las fases larvales y juveniles de estas especies en cultivo en Chile y comprobar su actividad patogénica mediante el desarrollo de bioensayos en condiciones controladas para poder contar con un cepario de cepas patogénicas que permita realizar ensayos de antagonismo bacteriano si es que se desea implementar estrategias de control sanitario, por ejemplo, mediante el uso de agentes probióticos.

\section{Agentes PRobióticos de USO POTENCIAL EN EL CUlTivo DE MOLUSCOS}

Existen diversos antecedentes que indican que bacterias benéficas o antagonistas de patógenos bacterianos pueden cumplir una función importante como probióticos en cultivos de moluscos al ejercer una actividad inhibidora de patógenos y/o mejorar la condición nutricional de las especies en cultivo (Riquelme et al. 1997, Gómez-Gil et al. 2000, Lim et al. 2011). En Chile, se ha desarrollado un gran número de estudios con el objetivo de aislar y caracterizar cepas bacterianas que presenten propiedades inhibitorias y que puedan constituirse en buenos candidatos como agentes probióticos para ser utilizados en cultivos de moluscos (Tabla 2). La mayoría de las investigaciones sobre el uso de agentes probióticos en cultivos de moluscos en Chile se ha circunscrito al cultivo de $A$. purpuratus (Jorquera et al. 1999, Riquelme et al. 1996a, 2000, Leyton \& Riquelme 2008b). Estos estudios han sugerido el reemplazo de la administración de terapias antimicrobianas por el uso de bacterias probióticas para el control de patógenos bacterianos en el cultivo del ostión del norte, no obstante, éstos sólo se han ensayado en cultivos experimentales a pequeña escala (Riquelme et al. 1997, Avendaño \& Riquelme 1999).

Se han realizado diversos estudios para comprobar en condiciones experimentales la actividad inhibitoria de bacterias aisladas de diferentes orígenes sobre cepas patógenas de larvas de A. purpuratus (Tabla 2). Una de las primeras cepas bacterianas con potencial probiótico fue aislada de las gónadas de este molusco y fue identificada como Alteromonas haloplanktis, presentando una actividad inhibitoria sobre cepas de Vibrio sp. y Aeromonas hydrophila, patógenos de moluscos (Riquelme et al. 1996a). En un estudio posterior, se evidenció que representantes de los géneros Artrobacter y Pseudomonas presentaron una capacidad de inhibición de cepas patógenas (Riquelme et al. 2000). Otra cepa bacteriana aislada desde agua de mar e identificada como Vibrio sp. presentó la capacidad de inhibir in vitro a una cepa patógena de $V$. anguillarumrelated, y además fue capaz de proteger larvas de ostión infectadas experimentalmente, exhibiendo una

Tabla 2. Actividad de bacterias probióticas contra patógenos de moluscos en Chile / Activity of probiotic bacteria against mollusc pathogens in Chile

\begin{tabular}{|c|c|c|c|c|c|}
\hline Molusco beneficiado & Etapa & Especie probiótica & Especie patogénica & Ensayo & Referencia \\
\hline Argopecten purpuratus & Larva & Alteromonas haloplanktis & Vibrio sp., Aeromonas hydrophila & in vivo & Riquelme et al. 1996a \\
\hline Argopecten purpuratus & Larva & Vibrio sp. & Vibrio anguillarum-related & in vivo & Riquelme et al. 1997 \\
\hline Argopecten purpuratus & Larva & Arthrobacter sp. & Vibrio anguillarum-related & in vivo & Riquelme et al. 2000 \\
\hline Argopecten purpuratus & Larva & Pseudomonas sp. & Vibrio anguillarum-related & in vivo & Riquelme et al. 2000 \\
\hline Argopecten purpuratus & Larva & Bacillus sp. & Vibrio anguillarum-related & in vivo & Riquelme et al. 2001 \\
\hline Concholepas concholepas & Larva & Bacillus sp. & Vibrio parahaemolyticus & in vitro & Leyton \& Riquelme 2010 \\
\hline Concholepas concholepas & Larva & Bacillus pumilus & Vibrio parahaemolyticus & in vitro & Leyton \& Riquelme 2010 \\
\hline Concholepas concholepas & Larva & Bacillus pumilus & Vibrio parahaemolyticus & in vivo & Leyton et al. 2012 \\
\hline Haliotis rufescens & Juvenil/adulto & Vibrio sp. & Vibrio parahaemolyticus & in vivo & Silva-Aciares et al. 2011 \\
\hline Haliotis rufescens & Juvenil/adulto & Vibrio sp. & Vibrio parahaemolyticus & in vivo & Silva-Aciares et al. 2011 \\
\hline Haliotis rufescens & Juvenil/adulto & Agarivorans albus & Vibrio parahaemolyticus & in vivo & Silva-Aciares et al. 2011 \\
\hline
\end{tabular}


potencialidad para ser utilizada como probióticos en cultivos de esta especie (Leyton \& Riquelme 2008a).

Los estudios de probióticos en otras especies de moluscos son bastante escasos, aunque recientemente se ha investigado la capacidad de cepas del género Bacillus aisladas desde gónadas y cápsulas de $C$. concholepas para inhibir al patógeno V. parahaemolyticus (Leyton \& Riquelme 2010), pudiendo así aumentar la sobrevivencia larval (Leyton et al. 2012). Debido al alto valor comercial de este gasterópodo, estas bacterias presentan interesantes propiedades que eventualmente podrían ser utilizadas para mejorar la producción de semillas en hatchery, aunque aún se requiere implementar el escalamiento del cultivo a nivel piloto para que esta tecnología esté al alcance de empresas cultivadoras de moluscos.

También existen estudios realizados en $H$. rufescens, donde se ha comprobado la actividad antagonista de cepas pertenecientes a los géneros Bacillus y Vibrio, así como a la especie Agarivorans albus (Silva-Aciares et al. 2013). Además, demostraron que ejemplares de este gasterópodo alimentados con probióticos y desafiados con $V$. parahaemolyticus, experimentan cambios metabólicos a nivel transcriptómico, como una menor expresión de genes en respuesta a estrés, y una mejor condición inmune, en comparación cuando no se adicionan probióticos, lo que podría explicar el efecto benéfico de estas bacterias (Silva-Aciares et al. 2013).

Con la finalidad de avanzar en el uso de bacterias benéficas a nivel industrial, se han realizado una serie de ensayos para identificar la mejor vía de administración de estas bacterias a los sistemas de cultivos larvales. Algunas experiencias realizadas en larvas de A. purpuratus muestran que las larvas son capaces de ingerir bacterias en forma selectiva (Araya et al. 1999) y que la ingestión del probiótico puede producirse cuando es inoculado directamente al agua o asociado con una microalga, lo que va a depender del tipo de bacteria a administrar (Avendaño \& Riquelme 1999). Otra vía de ingreso de bacterias al sistema de cultivo es a través de los reproductores, ya que se ha reportado que bacterias benéficas son capaces de colonizar y permanecer en las gónadas de los reproductores de A. purpuratus (Avendaño-Herrera et al. 2001), por lo cual se podrían incorporar bacterias benéficas a los cultivos larvales mediante su transmisión vertical (Jorquera et al. 2001). Cabe hacer notar que uno de los mejores resultados obtenidos en relación a las vías de administración de bacterias probióticas ha sido su administración directa en el agua de cultivo, obteniéndose niveles de mortalidad larval similares a aquellos observados en los cultivos larvales sometidos a terapia antibiótica, no observándose efectos negativos (Riquelme et al. 2001).

También se han realizado algunos estudios que han analizado los compuestos inhibitorios producidos por las bacterias antagonistas, con el objeto de dilucidar sus mecanismos de acción y desarrollar nuevos productos farmacéuticos. Es así que Jorquera et al. (1999) estudiaron una cepa de Vibrio sp. que exhibió una actividad bacteriostática sobre 14 especies bacterianas, la mayoría pertenecientes al género Vibrio y detectaron que la actividad inhibitoria estaba mediada por una molécula del tipo hidroxil éter alifático, aunque posteriormente una mayor purificación de este compuesto permitió determinar que se trataba de un ácido oleico (Leyton et al. 2011). En otros estudios se ha determinado la producción de compuestos peptídicos con propiedades antibacterianas por cepas de Alteromonas sp. (Riquelme et al. 1996a, León et al. 2005) y recientemente se han detectado moléculas con actividad bacteriostática producidas por cepas de Pseudoalteromonas sp. aisladas de Perumytilus purpuratus (Aranda et al. 2012).

En otro estudio se analizó la factibilidad del uso de biopelículas bacterianas para favorecer el asentamiento de post-larvas en hatcheries de moluscos, observándose que el tratamiento con bacterias perifíticas de colectores utilizados para la fijación de larvas de $A$. purpuratus puede producir un aumento de más del $200 \%$ en el asentamiento de larvas competentes (Avendaño-Herrera et al. 2002). Como se ha sugerido en diversos estudios, el uso de biopelículas compuestas por bacterias con propiedades de interés podrían ser de utilidad en hatcheries a nivel comercial (Avendaño-Herrera et al. 2002, Riquelme \& Avendaño-Herrera 2003, Silva-Aciares \& Riquelme 2008), logrando estimular el asentamiento del H. rufescens (Araya et al. 2010, Silva-Aciares et al. 2011) y A. purpuratus (Avendaño-Herrera \& Riquelme 2007, Leyton \& Riquelme 2008b), aunque su uso no ha resultado efectivo para el asentamiento de $A$. purpuratus en el medio natural (Cantillánez et al. 2010). Las biopelículas bacterianas también podrían producir sustancias inhibitorias que controlen micro-hábitat epifíticos (Avendaño-Herrera et al. 2005) y eviten el desarrollo del biofouling (Ayala et al. 2006, Zapata et al. 2007).

Las técnicas habituales para la obtención de bacterias con propiedades benéficas incluyen el aislamiento bacteriano desde la especie de molusco a cultivar o su ambiente circundante (Riquelme et al. 1997, Leyton \& 
Riquelme 2010), para así asegurar la supervivencia y multiplicación de las bacterias en ese ambiente y poder ejercer así su efecto benéfico para los moluscos en cultivo (Verschuere et al. 2000). Posteriormente se realiza un proceso de selección bacteriana que incluye diversos ensayos de antagonismo, donde los potenciales probióticos son analizados mediante ensayos de inhibición de patógenos de interés (Dopazo et al. 1988) y luego se realiza el bioensayo a pequeña escala, en el cual la cepa probiótica se administra a un cultivo del molusco en condiciones controladas para confirmar su inocuidad y su efecto en el aumento de la sobrevivencia y tasa de crecimiento larval (Avendaño-Herrera et al. 2002). Estos ensayos, si bien son útiles para reducir el número de cepas a examinar, y permiten identificar cepas con grandes potencialidades probióticas, no aseguran su éxito al ser administradas en el cultivo intensivo, por lo que se requiere comprobar su efectividad en ensayos in vivo a escala piloto. Esto último implica considerar la forma de administración más idónea para asegurar la mayor viabilidad del agente probiótico en el sistema de cultivo, y así confirmar el resultado obtenido en el bioensayo previo (Riquelme et al. 2001). Todas las etapas para la selección y desarrollo de un buen candidato probiótico para moluscos bivalvos ya han sido realizadas en Chile, constituyéndose en un país con un desarrollo importante en la investigación en esta área (Prado et al. 2010), aunque aún no se ha implementado su uso a escala comercial. Lo anterior es de gran relevancia pues está bien establecido que el uso de cepas bacterianas aisladas y ensayadas en un hatchery asociado a una determinada especie y condiciones de cultivo, presentan una mayor efectividad probiótica que aquellas cepas bacterianas adquiridas en el comercio y que están destinadas para su uso en otros recursos hidrobiológicos como peces (Aguilar-Macías et al. 2010).

En conclusión, la OIE (Office International des Epizooties) no considera los patógenos bacterianos de larvas de moluscos en su Código Sanitario, por lo que no se ha autorizado el uso de fármacos o la vigilancia de estos patógenos bacterianos en sistemas de cultivo, por ende no existen regulaciones sanitarias para esta industria. Lo anterior ha dificultado la implementación de normas sanitarias que permitan estandarizar protocolos de monitoreo en los sistemas de cultivo que conlleven a la sistematización de registros de procesos patológicos en los cultivos comerciales. Además, el carácter de patógeno oportunista de la mayoría de los patógenos identificados como causantes de mortalidades masivas en algunos de estos cultivos dificulta un diagnóstico temprano y eficiente, pues no es factible el uso de técnicas inmunológicas o moleculares, de uso común para el diagnóstico de patógenos primarios de peces.

En general, se puede concluir que la gran mayoría de estudios relacionados con la identificación de patógenos bacterianos, así como la descripción de la composición de la microbiota asociada a cultivos de moluscos en Chile se refieren al cultivo larval del ostión del norte, $A$. purpuratus. Por ello es evidente la necesidad de la realización de estudios bacteriológicos en recursos tan importantes como Concholepas concholepas, Haliotis rufescens, Mesodesma donacium y Mytilus chilensis.

Es notoria la ausencia de estudios que identifiquen los patógenos bacterianos que en forma recurrente causan cuadros de mortalidades masivas en los cultivos de moluscos produciendo muchas veces la pérdida de batches larvales completos. Por ello, no es de extrañar que en la mayoría de los cultivos se asuma una posición de coexistencia con estos procesos patológicos sin pretender desarrollar estudios para conocer aspectos epidemiológicos de los mismos. Por lo tanto, es imperante la necesidad de implementar indicadores de calidad larval en sistemas de cultivo masivo de moluscos que permitan detectar en forma prematura un deterioro del cultivo que favorezca el desarrollo de patologías bacterianas oportunistas. Bajo esta premisa, Miranda et al. (2009) elaboraron un manual que describe los procedimientos para la medición de indicadores sanitarios, fisiológicos y nutricionales en cultivos larvales de A. purpuratus.

Considerando que las vibrionáceas han sido asociadas a diversos procesos patológicos en el cultivo de moluscos y que este grupo presenta una alta diversidad taxonómica, uno de los aspectos pendientes a investigar corresponde a la caracterización de genes asociados a factores de virulencia tales como la expresión de metaloproteasas, hemolisinas, sideróforos, y otros.

La incorporación de innovaciones para la producción de larvas y juveniles basadas en el biocontrol, puede lograr un impacto positivo en el abastecimiento de semillas para la acuicultura en áreas de manejo, mediante el incremento del volumen de producción de una especie determinada o bien de nuevas especies hidrobiológicas, y así contribuir a la diversificación de la industria acuícola, produciendo un impacto económico y social en el cultivo de moluscos en Chile. Es altamente recomendable que los hatcheries de moluscos controlen los parámetros bacteriológicos en sus instalaciones, consiguiendo un manejo adecuado de la microbiota larval y aplicando 
estrategias de control bacteriano como la fagoterapia, uso de prebióticos, probióticos o sinbióticos. Esta estrategia de manejo, además de evitar el potencial uso de antibióticos y sus consecuentes riesgos sanitarios y ambientales, puede lograr el aumento de la supervivencia larval y la tasa de crecimiento de los individuos, efectos altamente deseados desde el punto de vista productivo.

El uso de bacterias benéficas en hatcheries de moluscos se presenta como una estrategia interesante que podría mejorar el desarrollo y sobrevivencia de larvas y semillas de moluscos en cultivo, permitiendo asegurar la producción sin la necesidad del uso de antibióticos, especialmente en los casos en que en el mercado no disponga de agentes antibacterianos eficientes y que las patologías microbianas sean causadas por bacterias resistentes a los antimicrobianos de uso habitual en los hatcheries de moluscos. Existe un importante desarrollo científico en Chile referente a la selección y uso de probióticos principalmente en el cultivo larval de $A$. purpuratus, sin embargo, es necesario abordar otros cultivos de moluscos de interés comercial. A la fecha aún no se han podido obtener resultados exitosos a nivel intensivo y ningún cultivo comercial ha implementado alguna de estas innovaciones para el control sanitario de su cultivo de moluscos. Es por ello que uno de los grandes desafíos en esta área es lograr la implementación exitosa del uso de bacterias benéficas en la producción de larvas y semillas de moluscos a escala comercial, logrando mantener una comunidad bacteriana estable en los estanques de cultivo. Para ello se requiere un aumento significativo en el desarrollo de proyectos de investigación y transferencia tecnológica para la implementación de protocolos de uso de agentes probióticos o sus componentes bioactivos, que aumenten la eficiencia productiva y que su administración sea segura para los cultivos sujetos a estas innovaciones. Sólo una adecuada validación de estos protocolos a escala comercial en condiciones intensivas permitirá asegurar su reproducibilidad para que estas estrategias sustituyan al uso de agentes antimicrobianos y puedan utilizarse de manera rutinaria para el manejo sanitario en estos sistemas de cultivo.

\section{LITERATURA CITADA}

Aguilar-Macías O, J Ojeda-Ramírez, A Campa-Córdova \& P Saucedo. 2010. Evaluation of natural and commercial probiotics for improving growth and survival of the pearl oyster, Pinctada mazatlanica, during late hatchery and early field culturing. Journal of the World Aquaculture Society 41(3): 447-454
Aranda CP, C Valenzuela, J Barrientos, J Paredes, P Leal, M Maldonado, FA Godoy \& C Osorio. 2012. Bacteriostatic anti-Vibrio parahaemolyticus activity of Pseudoalteromonas sp. strains DIT09, DIT44 and DIT46 isolated from Southern Chilean intertidal Perumytilus purpuratus. World Journal of Microbiology and Biotechnology 28: 2365-2374.

Araya RA, MA Jorquera \& CE Riquelme. 1999. Asociación de bacterias al ciclo del Argopecten purpuratus. Revista Chilena de Historia Natural 72: 261-271.

Araya R, C Bahamondes, K Barahona \& F Silva-Aciares. 2010. Utilización de una biopelícula microalgal multiespecífica para optimizar la fijación larval y el crecimiento de abalón (Haliotis rufescens) en un criadero comercial. Revista de Biología Marina y Oceanografía 45(1): 59-69.

Avendaño RE \& C Riquelme. 1999. Establishment of mixedculture probiotics and microalgae as food for bivalve larvae. Aquaculture Research 30: 893-900.

Avendaño RE, CE Riquelme, R Escribano \& N Reyes. 2001. Sobrevivencia y crecimiento de post-larvas de Argopecten purpuratus (Lamarck, 1819) en Bahía Inglesa, Chile: efectos del origen, distribución en la bahía y bacterioflora larval. Revista Chilena de Historia Natural 74: 669-679.

Avendaño-Herrera RE \& CE Riquelme. 2007. Production of a diatom-bacteria biofilm in a photobioreactor for aquaculture applications. Aquacultural Engineering 36: 97-104.

Avendaño-Herrera RE, M Dekovic \& C Riquelme. 2001. Establishment of beneficial bacteria in the digestive tract and gonads for adult Argopecten purpuratus (Lamarck 1819) in mass culture. Revista de Biología Marina y Oceanografía 36: $31-41$.

Avendaño-Herrera R, C Riquelme \& F Silva. 2002. Utilización de biopelículas bacterianas en el asentamiento de larvas de Argopecten purpuratus (Lamarck 1819) en un hatchery comercial. Revista de Biología Marina y Oceanografía 37(1): 35-41.

Avendaño-Herrera R, M Lody \& CE Riquelme. 2005. Producción de substancias inhibitorias entre bacterias de biopelículas en substratos marinos. Revista de Biología Marina y Oceanografía 40(2): 117-125.

Ayala C, M Clarke \& C Riquelme. 2006. Inhibition of byssal formation in Semimytilus algosus (Gould, 1850) by a filmforming bacterium isolated from biofouled substrata in northern Chile. Biofouling 22(1): 61-68.

Campalans M \& KB Lohrmann. 2009. Histological survey of four species of cultivated molluscs in Chile susceptible to OIE notifiable diseases. Revista de Biología Marina y Oceanografía 44(3): 561-569.

Cantillánez M, C Riquelme \& M Avendaño. 2010. Evaluación en ambiente natural, del uso de biopelículas marinas en el asentamiento larval de Argopecten purpuratus (Lamarck, 1819). Latin American Journal of Aquatic Research 38(1): 47-56. 
Chávez P \& C Riquelme. 1994. Análisis de la calidad bacteriológica en reproductores de Argopecten purpuratus (Lamarck, 1819) para su uso en acuicultura. Revista Latinoamericana de Acuicultura 43: 96-99.

Di Salvo LH. 1990. Problemática del cultivo de ostiones. Enfermedades. En: Flores H \& C Miranda (eds). VI Taller de Acuicultura, pp 78-82. Universidad Católica del Norte, Coquimbo.

Di Salvo L. 1994. Chronic infection of broodstock as a potential source of substandard gametes and larval infection in Chilean scallop hatcheries. En: Proceedings of the 9th International Pectinid Workshop, Nanaimo, B.C., Canada, April 22-27, 1993. Canadian Technical Report of Fisheries and Aquatic Science 1: 107-113.

Dopazo C, L Lemos, J Bolinches, J Barja \& A Toranzo. 1988. Inhibitory activity of antibiotic-producing marine bacteria against fish pathogens. Journal of Applied Bacteriology 65: 97-101.

Elston RA. 1984. Prevention and management of infectious diseases in intensive mollusc husbandry. Journal of World Mariculture Society 15: 284-300.

Enríquez R \& R Villagrán. 2008. Chile's experience with developing abalone (Haliotis spp.) farming: opportunities and challenges. Revue Scientifique et Technique 27: 103112.

Farias A, I Uriarte \& P Varas. 1997. Estudio de los requerimientos nutricionales de ostión del norte Argopecten purpuratus (Lamarck, 1819) durante el acondicionamiento reproductivo. Revista de Biología Marina y Oceanografía 32: 127-136.

Faune C. 2003. Principales causas bacterianas de mortalidad en los primeros estadíos de desarrollo del abalón rojo (Haliotis rufescens). Tesis de Médico Veterinario, Facultad de Ciencias Veterinarias, Universidad Austral de Chile, Valdivia, 42 pp. <http://cybertesis.uach.cl/tesis/uach/2005/ fvr741c/doc/fvr741c.pdf >

Flores-Aguilar RA, A Gutierrez, A Ellwanger \& R SearcyBernal. 2007. Development and current status of abalone aquaculture in Chile. Journal of Shellfish Research 26: 705-711.

Gallardo JA \& JM Cancino. 2009. Effects of temperature on development and survival of embryos and on larval production of Chorus giganteus (Lesson, 1829) (Gastropoda: Muricidae). Revista de Biología Marina y Oceanografía 44(3): 595-602.

García-Tello P, V Ardiles \& JL Fajardo. 2002. Bacterias en la hemolinfa de Argopecten purpuratus (Lamark, 1819) (Bivalvia: Pectinidae). Revista de Biología Marina y Oceanografía 37(2): 147-149.

Godoy FA, M Espinoza, G Wittwer \& C Aranda. 2011. Caracterización de bacterias cultivables presentes en sistemas de cultivo de larvas de ostión chileno Argopecten purpuratus. Ciencias Marinas 37(3): 339-348.
Gómez-Gil B, A Roque \& JF Turnbull. 2000. The use and selection of probiotic bacteria for use in the culture of larval aquatic organisms. Aquaculture 191: 259-270.

González RC, K Brokordt \& KB Lohrmann. 2012. Physiological performance of juvenile Haliotis rufescens and Haliotis discus hannai abalone exposed to the withering syndrome agent. Journal of Invertebrate Pathology 111(1): $20-26$.

González R, KB Lohrmann, J Pizarro \& K Brokordt. 2014. Differential susceptibility to the Withering Syndrome agent and renal coccidia in juvenile Haliotis rufescens, Haliotis discus hannai and the interspecific hybrid. Journal of Invertebrate Pathology 116: 13-17.

Jorquera MA, CE Riquelme, LA Loyola \& LF Muñoz. 1999. Production of bactericidal substances by a marine vibrio isolated from cultures of the scallop Argopecten purpuratus. Aquaculture International 7: 433-448.

Jorquera MA, FR Silva \& CE Riquelme. 2001. Bacteria in the culture of the scallop Argopecten purpuratus (Lamarck 1819). Aquaculture International 9: 285-303.

Jorquera M, L Leyton \& C Riquelme. 2004. Bacteria of subclass $\gamma$-proteobacteria associated with commercial Argopecten purpuratus (Lamarck, 1819) hatcheries in Chile. Aquaculture 236: 37-51.

León J, G Tapia \& R Avalos. 2005. Purificación parcial y caracterización de una sustancia antimicrobiana producida por Alteromonas sp. de origen marino. Revista Peruana de Biología 12(3): 359-368.

Leyton Y \& C Riquelme. 2008a. Vibrios en los sistemas marinos costeros. Revista de Biología Marina y Oceanografía 43(3): 441-456.

Leyton Y \& C Riquelme. 2008b. Use of specific bacterialmicroalgal biofilms for improving the larval settlement of Argopecten purpuratus (Lamarck, 1819) on three types of artificial spat-collecting materials. Aquaculture 276: 78-82.

Leyton Y \& C Riquelme. 2010. Marine Bacillus spp. associated with the egg capsule of Concholepas concholepas (Common name 'Loco') have an inhibitory activity toward the pathogen Vibrio parahaemolyticus. Microbial Ecology 60: 599-605.

Leyton Y, J Borquez, J Darias, M Cueto, AR Díaz-Marrero \& C Riquelme. 2011. Oleic acid produced by a marine Vibrio spp. acts as an anti-Vibrio parahaemolyticus agent. Marine Drugs 9: 2155-2163.

Leyton Y, RA Varas-Psijas \& CE Riquelme. 2012. Probiotic activity of bacteria associated with egg capsules of Concholepas concholepas (common name 'Loco'). Aquaculture Research 43(8): 1089-1095.

Lim HJ, D Kapareiko, EJ Schott, A Hanif \& GH Wikfors. 2011. Isolation and evaluation of new probiotic bacteria for use in shellfish hatcheries: I. Isolation and screening for bioactivity. Journal of Shellfish Research 30(3): 609-615. 
Llanos J, M Cid, S Navarro, A Dinamarca \& P GarciaTello. 2002. Atypical bacteria accompanying the scallop Argopecten purpuratus. Investigaciones Marinas 30: 5759.

Lohrmann KB. 2009. How healthy are cultivated scallops (Argopecten purpuratus) from Chile? A histopathological survey. Revista de Biología Marina y Oceanografía 44(1): $35-47$.

Lohrmann K, A Brand \& S Feist. 2002. Comparison of the parasites and pathogens present in a cultivated and in a wild population of scallops (Argopecten purpuratus Lamarck, 1819 ) in Tongoy Bay, Chile. Journal of Shellfish Research 21(2): 557-561.

Márquez M, P Chávez \& C Riquelme. 1990. Presencia de vibrionáceas en el tracto digestivo de Concholepas concholepas (Bruguiere, 1789) (Mollusca, muricidae). Revista de Biología Marina 25(2): 27-34.

Martínez-Guzmán G. 2008. Control de la reproducción y producción de semillas de bivalvos en sistemas controlados. En: Lovatelli A, A Farias \& I Uriarte (eds). Estado actual del cultivo y manejo de moluscos bivalvos y su proyección futura: factores que afectan su sustentabilidad en América Latina. Taller Técnico Regional de la FAO. Puerto Montt. FAO Actas de Pesca y Acuicultura 12: 267-275. FAO, Roma.

Miranda CD, R Rojas \& L Hurtado. 2009. Manual técnico 'Indicadores de calidad larval del ostión del Norte', 65 pp. INNOVA Chile de CORFO / Universidad Católica del Norte, Coquimbo.

Miranda CD, R Rojas, A Abarca \& L Hurtado. 2014. Effect of florfenicol and oxytetracycline treatments on intensive larval culture of the Chilean scallop Argopecten purpuratus (Lamarck, 1819). Aquaculture Research 45: 16-30.

Miranda CD, R Rojas, M Garrido, J Geisse \& G González. 2013. Role of shellfish hatchery as a reservoir of antimicrobial resistant bacteria. Marine Pollution Bulletin 74(1): 334-343

Montenegro D, B Jones \& MT González. 2012. Report of pathogens and parasites in Perumytilus purpuratus from San Jorge Bay, Antofagasta, Chile. Revista de Biología Marina y Oceanografía 47: 345-350.

Pérez E, C Azócar, A Araya, O Astudillo \& M Ramos. 2012. Comparación del crecimiento de Argopecten purpuratus entre cohortes obtenidas de captación de larvas en ambiente natural y de hatchery. Latin American Journal of Aquatic Research 40: 1026-1038.

Prado S, J Romalde \& J Barja. 2010. Review of probiotic for use in bivalve hatcheries. Veterinary Microbiology 145: 187-197.

Riquelme CE \& RE Avendaño-Herrera. 2003. Interaction bacteria-microalga en el ambiente marino y uso potencial en acuicultura. Revista Chilena de Historia Natural 76: 725736.
Riquelme C, P Chávez, Y Morales \& G Hayashida. 1994. Evidence for parental bacterial transfer to larvae in Argopecten purpuratus (Lamarck, 1819). Biological Research 27: 129-134.

Riquelme C, G Hayashida, AE Toranzo, J Vilches \& P Chávez. 1995a. Pathogenicity studies on a Vibrio anguillarum related (VAR) strain causing an epizootic in Argopecten purpuratus larvae cultured in Chile. Disease Aquatic Organism 22: 135-141.

Riquelme C, G Hayashida, N Vergara, A Vásquez, Y Morales \& P Chávez. 1995b. Bacteriology of the scallop Argopecten purpuratus (Lamarck, 1819) cultured in Chile. Aquaculture 138(1): 49-60.

Riquelme C, G Hayashida, R Araya, A Uchida, M Satomi \& Y Ishida. 1996a. Isolation of native bacterial strain from the scallop Argopecten purpuratus with inhibitory effects against pathogenic vibrios. Journal of Shellfish Research 15(2): 369-374.

Riquelme C, AE Toranzo, JL Barja, N Vergara \& R Araya. 1996b. Association of Aeromonas hydrophila and Vibrio alginolyticus with larval mortalities of scallop (Argopecten purpuratus). Journal of Invertebrate Pathology 67: 213218

Riquelme CE, R Araya, N Vergara, A Rojas, M Guaita \& M Candia. 1997. Potential probiotic strains in the culture of the Chilean scallop Argopecten purpuratus (Lamarck, 1819). Aquaculture 154: 17-26.

Riquelme CE, R Araya \& R Escribano. 2000. Selective incorporation of bacteria Argopecten purpuratus larvae: implications for the use of probiotics in culturing systems of the Chilean scallop. Aquaculture 181: 25-36.

Riquelme CE, MK Jorquera, AI Rojas, RE Avendaño \& N Reyes. 2001. Addition of inhibitor-producing bacteria to mass cultures of Argopecten purpuratus larvae (Lamarck, 1819). Aquaculture 192: 111-119.

Rojas R, CD Miranda \& AM Amaro. 2009. Pathogenicity of a highly exopolysaccharide-producing Halomonas strain causing epizootics in larval cultures of the Chilean scallop Argopecten purpuratus (Lamarck, 1819). Microbial Ecology 57: 129-139.

Rojas R, CD Miranda, R Opazo \& J Romero. 2014. Characterization and pathogenicity of Vibrio splendidus strains associated with massive mortalities of commercial hatchery-reared larvae of scallop Argopecten purpuratus (Lamarck, 1819). Journal of Invertebrate Pathology 124C: 61-69. <doi:10.1016/j.jip.2014.10.009>.

Romalde J \& J Barja. 2010. Bacteria in molluscs: good and bad guys. Current research, technology and education topics in applied microbiology and microbial biotechnology, Microbiology Books Series 1(2): 136-147.

Romero J \& R Espejo. 2001. The prevalence of noncultivable bacteria in oysters (Tiostrea chilensis, Philippi, 1845). Journal of Shellfish Research 20: 1235-1240. 
Romero J, M García-Varela, JP Laclette \& RT Espejo. 2002. Bacterial 16S rRNA gene analysis revealed that bacteria related to Arcobacter spp. constitute an abundant and common component of the oyster microbiota (Tiostrea chilensis). Microbial Ecology 44: 365-371.

Sainz-Hernández JC \& A Maeda-Martínez. 2005. Sources of Vibrio bacteria in mollusc hatcheries and control methods: a case study. Aquaculture Research 36: 1611-1618.

Sandaa RA, T Magnesen, L Torkildsen \& Ø Bergh. 2003. Characterisation of the bacterial community associated with early stages of Great Scallop (Pecten maximus), using denaturing gradient gel electrophoresis (DGGE). Systematic and Applied Microbiology 26(2): 302-311.

Silva-Aciares F \& C Riquelme. 2008. Inhibition of attachment of some fouling diatoms and settlement of Ulva lactuca zoospores by film-forming bacterium and their extracelular products isolated from biofouled substrata in Northern Chile. Electronic Journal of Biotechnology 11(1): 60-70.

Silva-Aciares FR, PO Carvajal, CA Mejías \& CE Riquelme. 2011. Use of macroalgae supplemented with probiotics in the Haliotis rufescens (Swainson, 1822) culture in Northern Chile. Aquaculture Research 42: 953-961.

Silva-Aciares F, D Moraga, M Auffret, A Tanguy \& C Riquelme. 2013. Transcriptomic and cellular response to bacterial challenge (pathogenic Vibrio parahaemolyticus) in farmed juvenile Haliotis rufescens fed with or without probiotic diet. Journal of Invertebrate Pathology 113(2): 163-176.
Uriarte I. 2008. Estado actual del cultivo de moluscos bivalvos en Chile. En: Lovatelli A, A Farias \& I Uriarte (eds). Estado actual del cultivo y manejo de moluscos bivalvos y su proyección futura: factores que afectan su sustentabilidad en América Latina. Taller Técnico Regional de la FAO, Puerto Montt. FAO Actas de Pesca y Acuicultura 12: 61-75.

Uriarte I, A Farías \& J Castilla. 2001. Effect of antibiotic treatment during larval development of the Chilean scallop Argopecten purpuratus. Aquacultural Engineering 25: 139147.

Verschuere 1, G Rombaut, P Sorgeloos \& W Verstraete. 2000. Probiotic bacteria as biological bontrol agents in aquaculture. Microbiology and Molecular Biology Reviews 64(4): 655-671.

Wurmann-Gotfrit C. 2008. Problemática y desafíos de la producción chilena de moluscos bivalvos en pequeña escala. En: Lovatelli A, A Farias \& I Uriarte (eds). Estado actual del cultivo y manejo de moluscos bivalvos y su proyección futura: factores que afectan su sustentabilidad en América Latina. Taller Técnico Regional de la FAO, Puerto Montt. Actas de Pesca y Acuicultura 12: 343-359.

Zapata M, S Silva, Y Luza, M Wilkens \& C Riquelme. 2007. The inhibitory effect of biofilms produced by wild bacterial isolates to the larval settlement of the fouling ascidia Ciona intestinalis and Pyura praeputialis. Electronic Journal of Biotechnology 10(1): 149-159.

Recibido el 9 de junio de 2014 y aceptado el 12 de diciembre de 2014

Editor: Claudia Bustos D. 